Published in final edited form as:

Invest New Drugs. 2019 April ; 37(2): 315-322. doi:10.1007/s10637-018-0663-0.

\title{
Phase I Study Combining the Aurora Kinase A Inhibitor Alisertib with mFOLFOX in Gastrointestinal Cancer
}

\author{
Laura W. Goff ${ }^{1,2}$, Nilofer S. Azad ${ }^{3}$, Stacey Stein ${ }^{4}$, Jennifer G. Whisenant ${ }^{1,2}$, Tatsuki \\ Koyama $^{1,5}$, Ulka Vaishampayan ${ }^{6}$, Howard Hochster ${ }^{7}$, Roisin Connolly ${ }^{3}$, Amy Weise ${ }^{6}$, \\ Patricia M. LoRusso ${ }^{4}$, Safia N. Salaria ${ }^{1}$, Wael EI-Rifai ${ }^{8}$, and Jordan D. Berlin ${ }^{1,2}$ \\ ${ }^{1}$ Vanderbilt-Ingram Cancer Center, Vanderbilt University Medical Center, Nashville, TN, USA \\ ${ }^{2}$ Department of Medicine, Vanderbilt University Medical Center, Nashville, TN, USA \\ 3Johns Hopkins Sidney Kimmel Comprehensive Cancer Center, Baltimore, MD, USA \\ ${ }^{4}$ Yale Cancer Center, Yale School of Medicine, New Haven, CT, USA \\ ${ }^{5}$ Department of Biostatistics, Vanderbilt University Medical Center, Nashville, TN, USA \\ ${ }^{6}$ Karmanos Cancer Institute, Detroit, MI, USA \\ ${ }^{7}$ Rutgers Canter Institute, New Brunswick, NJ, USA \\ 8University of Miami Sylvester Comprehensive Cancer Center, Miami, FL, USA
}

\section{Abstract}

Overexpression and cellular miss-localization of aurora kinase A (AURKA) in gastrointestinal cancers results in chromosomal instability, activation of multiple oncogenic pathways, and inhibition of pro-apoptotic signaling. Inhibition of AURKA causes mitotic delays, severe chromosome congression, and activation of p53/p73 leading to cell death. Our preclinical data showed cooperative activity with the AURKA inhibitor alisertib and platinum agents in cell lines and xenografts, and suggested an optimal treatment window. Therefore, this study was designed to determine the maximum-tolerated dose (MTD) of alisertib in combination with modified FOLFOX (mFOLFOX), as this is a standard platinum-based therapy for gastrointestinal cancers. Standard $3+3$ dose escalation was used, where the starting dose of alisertib was $10 \mathrm{mg}$ twice daily

Corresponding author: Laura W. Goff, MD Vanderbilt University 2220 Pierce Avenue PRB 777, Nashville, TN 37232 Phone: 615-936-8422, Fax: 615-343-7602 Laura.goff@ vanderbilt.edu.

\section{COMPLIANCE WITH ETHICAL STANDARDS}

Conflicts of interest

LWG has served as a consultant for Celgene and has institutional research funding from Astellas Pharma, Pfizer, Onxy, SunPharma, Lilly, and Bristol-Myers Squibb. SS has participated in advisory boards for Genentech Roche and Merck. HH has served as a consultant for Bayer, Genentech, and Merck. RC has received research grants from Macrogenics, Novartis, Puma Biotechnology, Merck, Merrimack, and Genentech. JB has served as a consultant for Celgene, Genentech, Aduro, Boston Biomedical, Janssen, Cornerstone, Symphogen, and Bayer and has institutional research funding from Genentech, Abbvie, Taiho, Bayer, 5Prime, Phoenix, Incyte, and Vertex. For the remaining authors, none were declared.

Ethical approval

All procedures performed in studies involving human participants were in accordance with the ethical standards of the institutional and/or national research committee and with the 1964 Helsinki declaration and its later amendments or comparable ethical standards.

Informed consent

Informed consent was obtained for all individual participants included in the study. 
(Days 1-3), with leucovorin $\left(400 \mathrm{mg} / \mathrm{m}^{2}\right)$ and oxaliplatin $\left(85 \mathrm{mg} / \mathrm{m}^{2}\right)$ on Day 2 followed by continuous 46-hour 5-FU $\left(2400 \mathrm{mg} / \mathrm{m}^{2}\right)$ infusion on Days 2-4 in 14-day cycles. Fourteen patients with advanced gastrointestinal cancers were enrolled and two doses explored; two patients were not evaluable for dose-limiting toxicity (DLT) and replaced. Two patients experienced DLTs at 20 mg of alisertib (Grade 3 fatigue ( $n=2$ ); Grade 3 nausea, vomiting, dehydration with hospitalization $(\mathrm{n}=1))$. MTD was $10 \mathrm{mg}$ alisertib with $85 \mathrm{mg} / \mathrm{m}^{2}$ oxaliplatin and $2400 \mathrm{mg} / \mathrm{m}^{2} 5$-FU. Most frequent toxicities were nausea (57\%), diarrhea, fatigue, neuropathy, and vomiting $(43 \%)$, and anorexia and anemia (36\%); most were Grade 1-2. One patient with colorectal cancer had a partial response of 12 evaluable patients, and four patients had stable disease. Alisertib in combination with mFOLFOX did not demonstrate unexpected side effects, but the regimen was only tolerable at the lowest dose investigated.

\section{Keywords}

alisertib; gastrointestinal cancers; aurora kinase A inhibition; modified FOLFOX

\section{INTRODUCTION}

The aurora kinase family of serine/threonine kinases has three members, designated aurora kinases A, B, and C [1]; kinases A and B are expressed in many different cell types, whereas the expression of kinase $\mathrm{C}$ is restricted to testicular tissue. Aurora kinases localize in the centrosome and play a crucial role in cell division by regulating the segregation of chromatid in cells undergoing mitosis [2]. Specifically, aurora kinase A (AURKA) is located at the centrosome in early $\mathrm{S}$ phase, and a fraction associates with the mitotic spindle during cell division [2-4]. Because AURKA is required for cytokinesis, inhibition of AURKA causes spindle pole and chromosome congression defects leading to aneuploidy, which is then followed by cell death [5-8]. Knockdown of AURKA was shown to suppress centrosome maturation [4,9]; in mice, genetic ablation or null mutation of AURKA caused mitotic arrest and embryonic death [10-12].

In addition to its primary effects on the cell cycle, AURKA appears to have a role in oncogenic signaling, including c-MYC, CCND1, and VEGF [13,14]. Several studies have shown that AURKA overexpression directly leads to malignant transformation and subsequently tumor formation [15-17]. Overexpression or amplification of AURKA has been identified in several solid malignancies, including colorectal, gastric, esophageal, liver, and pancreas cancers $[18,15,19-23]$. Notably, overexpression was observed in multiple aggressive gastrointestinal adenocarcinomas [24,25]. Furthermore, it has been suggested that AURKA is an essential mediator of chemo-resistance in colorectal cancer [26]. Collectively, these findings strongly suggest that targeting AURKA, either alone or combination, in gastrointestinal cancers may represent an attractive treatment option.

Alisertib (MLN8237) is an oral, selective inhibitor of AURKA [27]. In preclinical studies, single agent alisertib showed potent inhibition of AURKA and high antitumor activity [27,28], as well induced abnormal G2/M cell cycle arrest in upper gastrointestinal cancers [29-31]. Combination studies in multiple in vitro and in vivo models demonstrated additive 
activity or better. Combination treatment with docetaxel enhanced apoptosis and antitumor activity in lymphoma [32] and upper gastrointestinal adenocarcinomas [31]. In B-cell NonHodgkin Lymphoma, alisertib administered with vincristine and rituximab resulted in robust cell death [33].

We have previously observed an added benefit of combining alisertib with platinum agents, both cisplatin and oxaliplatin, in multiple human esophageal (FLO-1) and gastric cancer (AGS, Kato-III) cell lines, as well as two esophageal (FLO-1 and OE33) xenograft models $[34,35]$. Based on our preclinical data, we designed a phase I study to evaluate safety and tolerability of alisertib in combination with modified FOLFOX (mFOLFOX) in patients with gastrointestinal cancers. Additionally, our observations from the in vitro and in vivo studies indicated that alisertib has a delayed apoptotic effect, inducing polyploidy in the first 24 hours followed by cell death in 72-96 hours, suggesting an optimal timing window. Antitumor activity was evaluated as a secondary objective. Exploratory correlatives were performed to evaluate the potential relationship between expression levels of AURKA and cMYC with tumor response.

\section{MATERIALS AND METHODS}

\section{Patient Selection}

This investigator-initiated, multiple-institution phase I study (NCT02319018) of alisertib with mFOLFOX was conducted in patients with metastatic or unresectable gastrointestinal cancers where standard therapies did not exist or were no longer effective, or for whom FOLFOX was appropriate. Eligible patients were $>18$ years of age with an Eastern Cooperative Oncology Group (ECOG) performance status (PS) of 0-1, had adequate organ and marrow function, were able to swallow oral medication, and did not have grade $\geq 2$ peripheral neuropathy. Prior treatment with FOLFOX was allowed.

\section{Study Treatment}

Dose escalation (Table 1) began with $10 \mathrm{mg}$ of alisertib twice daily on Days 1-3, with leucovorin and oxaliplatin $\left(85 \mathrm{mg} / \mathrm{m}^{2}\right)$ on Day 2 followed by continuous 5-FU (2400 $\mathrm{mg} / \mathrm{m}^{2}$ ) infusion on Days 2-4 in 14-day cycles. The mFOLFOX regimen did not include the 5-FU bolus as previous study demonstrated that the bolus is responsible for most of the cytopenias and could be removed without compromising efficacy [36]. Dose escalation was planned for groups of three patients until the maximum-tolerated dose (MTD) was established in a standard 3+3 design. Dose limiting toxicity (DLT) was defined as any treatment-related, Grade $\geq 3$ non-hematologic toxicity (except nausea, vomiting, and diarrhea) or Grade $\geq 4$ hematologic toxicity experienced within the first two cycles ( 28 days). Nausea, vomiting, or diarrhea were dose limiting when Grade 3 toxicity occurred despite optimal use of anti-emetic or anti-diarrheal agents, or lasted longer than 48 hours. A treatment delay of $>21$ days due to a treatment-related toxicity was also dose limiting. Patients must have received two doses of mFOLFOX and at least $80 \%$ of the planned doses of alisertib to be evaluable for DLT, unless missed doses were due to a DLT. 
Patients continued on study until unacceptable toxicity, disease progression, patient withdrawal, or specific changes in a patient's condition that, in the judgment of the investigator, rendered the patient unacceptable for further treatment. Patients were followed for four weeks after removal from the study or until death, whichever occurred first. Patients removed from study due to unacceptable adverse events were followed until resolution or stabilization of the adverse event.

\section{Study Assessments}

Toxicity assessments were performed at each cycle and graded according to the NCI Common Toxicity Criteria, Version 4.0. Patients were evaluable for toxicity from the time of their first treatment with alisertib. Patients that were removed from the study during the first four weeks of treatment for reasons other than progressive disease or drug-related adverse events were not considered evaluable for DLT and were replaced; however, these patients were evaluable for toxicity. Disease assessments were performed at baseline and every eight weeks using RECIST v1.1. Only those patients that had measurable disease at baseline, received at least one cycle of therapy, and had their disease re-evaluated were evaluable for response. Patients who were removed during the first two cycles due to progressive disease were also evaluable for response.

\section{Correlative Biomarker Analysis}

The primary goal of the correlative studies was to explore the feasibility of performing biomarker assays on human samples in gastrointestinal cancers and guide biomarker development for later phase studies. Consenting patients provided archival tissue. Immunohistochemistry (IHC) for expression levels of AURKA and c-MYC was performed using a rabbit anti-human AURKA polyclonal antibody (Transgenic Inc., Japan) and a rabbit monoclonal [Y69] anti-human c-Myc (Abcam, USA), respectively, following the manufacturers' recommended protocols.

\section{Statistical Analysis}

Descriptive statistics were used to summarize demographics, adverse events, and tumor response. Confidence intervals were estimated using the Wilson method, and survival functions were estimated using the Kaplan-Meier method. Correlations between tumor response and expression levels of AURKA and c-MYC were evaluated.

\section{RESULTS}

\section{Patient Characteristics}

Between November 2015 and February 2017, 14 patients were enrolled and two dose levels were investigated. Baseline patient characteristics are listed in Table 2. One patient exhibited disease progression prior to completing the DLT observation window and was replaced. Another patient was found to be receiving prohibited medications during the DLT observation window and was replaced. Median age was 59 years (range: 27-80) and 64\% were male. Various gastrointestinal malignancies were evaluated: colon $(n=4)$, pancreas $(n=4)$, stomach $(n=2)$, bile duct $(n=2)$, esophagus $(n=1)$, and appendix $(n=1)$. Twelve 
patients were evaluable for toxicity. Of these 12 , two came off study due to unacceptable toxicity while the remaining 10 continued treatment until disease progression.

\section{Treatment and Toxicities}

Three patients were enrolled in dose level 1, and zero DLTs were observed. At dose level 2 (20 mg BID alisertib, $85 \mathrm{mg} / \mathrm{m}^{2}$ oxaliplatin, and $2400 \mathrm{mg} / \mathrm{m}^{2} 5-\mathrm{FU}$ ), two of three patients experienced DLTs: Grade 3 fatigue ( $\mathrm{n}=2)$; Grade 3 nausea, vomiting, and dehydration with hospitalization ( $\mathrm{n}=1)$. Alisertib was de-escalated to $10 \mathrm{mg}$ twice daily (dose level 1 ) and three additional patients were enrolled; no DLTs observed. Thus, the MTD was $10 \mathrm{mg}$ BID alisertib, $85 \mathrm{mg} / \mathrm{m}^{2}$ oxaliplatin, $400 \mathrm{mg} / \mathrm{m} 2$ leucovorin and $2400 \mathrm{mg} / \mathrm{m}^{2} 5-\mathrm{FU}$.

The most common treatment-related toxicities were nausea (57\%), diarrhea (43\%), fatigue $(43 \%)$, peripheral sensory neuropathy (43\%), vomiting (43\%), anorexia (36\%), and anemia (36\%); a majority of these were Grade 1-2. Other frequently observed ( $>20 \%)$ adverse events are listed in Table 3. Eight patients experienced at least one Grade 3 adverse event, with the most common being neutropenia (29\%). Treatment-related Grade 4 hypokalemia was reported in one patient. All Grade 3-4 adverse events are listed in Table 3.

\section{Antitumor Activity}

One patient did not have measurable disease at baseline and was not evaluable for response. Of the 12 evaluable patients (Table 4), one patient with colon cancer had a partial response for an $8.3 \%$ response rate; this patient had prior FOLFOX in the adjuvant setting.

Interestingly, AURKA was amplified in the tumor of this patient. An additional four patients had stable disease for a $42 \%$ disease control rate; of these patients, one had adjuvant FOLFOX, one had FOLFOX and CAPOX for the treatment of advanced disease, and the remaining two did not have prior FOLFOX. One patient with esophageal cancer achieved a $-28 \%$ tumor regression, but unfortunately came off study after four cycles due to excessive toxicity. The median time on treatment was 1.9 months (Figure 1B, Figure 2A; range: $0.5-$ 9.2 months); two patients with colon cancer were on study longer than six months. The overall mean progression-free survival (PFS) was 2.3 months (95\% confidence interval: 1.4 -6.2 months).

\section{Correlative Biomarker Analysis}

Expression levels of AURKA and c-MYC were analyzed using archival tissue from six patients. Representative IHC sections are shown for two patients in Supplemental Figure 1, showing minimal cytosolic staining of AURKA and c-MYC and varying degree of nuclear staining for both markers. IHC scores, primary site of disease, and best response for the six patients are listed in Supplemental Table 1. A correlation between expression levels of AURKA and c-MYC with tumor response was not observed, possibly due to the small number of tissues analyzed.

\section{DISCUSSION}

Gastrointestinal cancers are a leading cause of cancer-related deaths; specifically, in the United States, colorectal cancers are the second and third leading cancer-related deaths in 
men and women, respectively [37]. Moreover, the number of pancreatic cancer deaths have been on the rise for the past few decades [37]. Esophageal and gastric cancers, although more rare than other gastrointestinal cancers, are also deadly with $<10 \% 5$-year survival for patients with metastatic disease [38]. Thus, the need for novel treatment modalities and targeted therapeutics, that are based on the molecular features of these tumors, are needed to improve survival. Our preclinical data showed that inhibiting AURKA in combination with platinum-based chemotherapies significantly decreased cell viability and survival, as well as significantly inhibited xenograft tumor growth in multiple gastrointestinal cancer models compared to either single agent alone, thus, suggesting a potential synergistic treatment combination. Based on these data, a phase I study was designed to assess the safety and tolerability of alisertib in combination with mFOLFOX, as this is an appropriate platinumbased chemotherapy regimen for most gastrointestinal cancers.

In general, alisertib administered with mFOLFOX did not identify any unexpected side effects. The toxicity profile was similar to a phase II study investigating single agent alisertib in gastroesophageal adenocarcinoma [39], with the exception of increased frequencies of leukopenia, nausea, and decreased appetite that is probably attributable to FOLFOX. However, alisertib in combination with FOLFOX was only tolerable at the lowest dose evaluated (i.e., $10 \mathrm{mg} \mathrm{BID}$ ), which is significantly lower than the recommended phase II dose (RP2D) of single-agent alisertib (50 mg BID) [39-41]. The 5-FU bolus was already removed to reduce the frequency of neutropenias, therefore it was decided not to decrease the dose 5-FU or oxaliplatin in order to increase alisertib as those standard doses have a known benefit in patients with gastrointestinal malignancies.

Of the 12 patients with measureable disease, clinical activity was seen in approximately half (42\%). Two patients with colon cancer were on study longer than six months, and one of those patients achieved a partial response. Both patients had previously received FOLFOX in the adjuvant setting. Interestingly, AURKA was amplified in the tumor of the responder. (Unfortunately, the AURKA status was unknown in the other colon cancer patient.) Alisertib in combination with mFOLFOX in the current study resulted in less clinical activity than other combination studies. A phase I study of alisertib with docetaxel demonstrated a $28 \%$ response rate in advanced solid tumors [42]. Another phase I study in neuroblastoma observed an overall response rate of $31.8 \%$ (50\% response rate in patients treated at the MTD) when alisertib was combined with irinotecan and temozolomide [43].

The limited clinical activity observed in this study could be attributed to a number of factors. Variable IC50 values of alisertib have been shown across multiple cancer models; an IC $_{50}$ of $2 \mathrm{nM}$ was observed in chronic myeloid leukemia [44,45]. Yet in other cancers, $\mathrm{IC}_{50}$ values range from $6.7 \mathrm{nM}$ in cervical (HeLa) cancer cells to as high as $469 \mathrm{nM}$ in the DLD-1 colon cancer cell line [27]. Furthermore, Pitts, $\boldsymbol{e t}$ al. demonstrated varying sensitivity to alisertib across multiple colorectal cancer cell lines and xenograft models [46], which might explain the variable clinical activity observed in this study, especially between the patients with colorectal cancer. Another logical reason for the limited clinical activity could be the associated toxicity with the combination regimen. The only tolerable dose of alisertib was 10 $\mathrm{mg}$ BID in combination with the standard dose of mFOLFOX, which is significantly lower than the RP2D of single-agent alisertib. 
Despite the potential for differences in alisertib sensitivity between patients in this trial combined with the low tolerable dose, two patients were on study longer than six months and one of those patients achieved a partial response. Thus, alisertib administered with oxaliplatin-based regimens could be beneficial in patients with gastrointestinal malignancies, especially in those whose tumors have alterations in AURKA expression or function. However, a phase II study requiring an AURKA alteration or overexpression for inclusion would be needed in order to fully characterize the antitumor activity of this regimen in gastrointestinal cancers.

\title{
CONCLUSIONS
}

This Phase I study was designed to evaluate a novel therapeutic regimen, combining the AURKA inhibitor alisertib with mFOLFOX in patients with advanced gastrointestinal cancers. Although this regimen was safe with manageable side effects, alisertib in combination with standard FOLFOX was only tolerable at the lowest dose evaluated; the MTD was $10 \mathrm{mg}$ BID alisertib administered with $85 \mathrm{mg} / \mathrm{m}^{2}$ oxaliplatin and $2400 \mathrm{mg} / \mathrm{m}^{2} 5$ FU. Limited clinical activity was observed; however, one patient whose tumor overexpressed AURKA experienced a partial response, suggesting the need to further explore biomarkers of AURKA inhibition to select patients who may potentially benefit from AURKA inhibitors in gastrointestinal malignancies.

\section{Supplementary Material}

Refer to Web version on PubMed Central for supplementary material.

\section{ACKNOWLEDGEMENTS}

\begin{abstract}
The authors would like to thank the patients who participated in this study and their families, the study investigators, and study staff. We would also like to thank the National Cancer Institute Clinical Trials Evaluation Program (NCI Trial \#9824), the Vanderbilt-Ingram Cancer Center (P30 CA068485), and the National Institutes of Health (UM1 CA186689) for sponsoring this study.

Funding

We would like to thank the National Cancer Institute Clinical Trials Evaluation Program (NCI Trial \#9842), the Vanderbilt-Ingram Cancer Center (P30 CA068485), and the National Institutes of Health (UM1 CA186689) for sponsoring this study.
\end{abstract}

\section{REFERENCES}

1. Boss DS, Beijnen JH, Schellens JH (2009) Clinical experience with aurora kinase inhibitors: a review. Oncologist 14 (8):780-793. doi:10.1634/theoncologist.2009-0019 [PubMed: 19684075]

2. Giet R, Prigent C (1999) Aurora/Ipl1p-related kinases, a new oncogenic family of mitotic serinethreonine kinases. Journal of cell science 112 ( Pt 21):3591-3601 [PubMed: 10523496]

3. Crane R, Gadea B, Littlepage L, Wu H, Ruderman JV (2004) Aurora A, meiosis and mitosis. Biol Cell 96 (3):215-229. doi:10.1016/j.biolcel.2003.09.008 [PubMed: 15182704]

4. Hannak E, Kirkham M, Hyman AA, Oegema K (2001) Aurora-A kinase is required for centrosome maturation in Caenorhabditis elegans. J Cell Biol 155 (7):1109-1116. doi:10.1083/jcb.200108051 [PubMed: 11748251]

5. Hoar K, Chakravarty A, Rabino C, Wysong D, Bowman D, Roy N, Ecsedy JA (2007) MLN8054, a small-molecule inhibitor of Aurora A, causes spindle pole and chromosome congression defects 
leading to aneuploidy. Mol Cell Biol 27 (12):4513-4525. doi:10.1128/MCB.02364-06 [PubMed: 17438137]

6. Marumoto T, Honda S, Hara T, Nitta M, Hirota T, Kohmura E, Saya H (2003) Aurora- A kinase maintains the fidelity of early and late mitotic events in HeLa cells. J Biol Chem 278 (51):5178651795. doi:10.1074/jbc.M306275200 [PubMed: 14523000]

7. Glover DM, Leibowitz MH, McLean DA, Parry H (1995) Mutations in aurora prevent centrosome separation leading to the formation of monopolar spindles. Cell 81 (1):95- 105 [PubMed: 7720077]

8. Katayama H, Zhou H, Li Q, Tatsuka M, Sen S (2001) Interaction and feedback regulation between STK15/BTAK/Aurora-A kinase and protein phosphatase 1 through mitotic cell division cycle. J Biol Chem 276 (49):46219-46224. doi:10.1074/jbc.M107540200 [PubMed: 11551964]

9. Hirota T, Kunitoku N, Sasayama T, Marumoto T, Zhang D, Nitta M, Hatakeyama K, Saya H (2003) Aurora-A and an interacting activator, the LIM protein Ajuba, are required for mitotic commitment in human cells. Cell 114 (5):585-598 [PubMed: 13678582]

10. Cowley DO, Rivera-Perez JA, Schliekelman M, He YJ, Oliver TG, Lu L, O'Quinn R, Salmon ED, Magnuson T, Van Dyke T (2009) Aurora-A kinase is essential for bipolar spindle formation and early development. Mol Cell Biol 29 (4):1059-1071. doi:10.1128/MCB.01062-08 [PubMed: 19075002]

11. Lu LY, Wood JL, Ye L, Minter-Dykhouse K, Saunders TL, Yu X, Chen J (2008) Aurora A is essential for early embryonic development and tumor suppression. J Biol Chem 283 (46):3178531790. doi:10.1074/jbc.M805880200 [PubMed: 18801727]

12. Yoon Y, Cowley DO, Gallant J, Jones SN, Van Dyke T, Rivera-Perez JA (2012) Conditional Aurora A deficiency differentially affects early mouse embryo patterning. Dev Biol 371 (1):77-85. doi: 10.1016/j.ydbio.2012.08.010 [PubMed: 22939930]

13. Otto T, Horn S, Brockmann M, Eilers U, Schuttrumpf L, Popov N, Kenney AM, Schulte JH, Beijersbergen R, Christiansen H, Berwanger B, Eilers M (2009) Stabilization of N-Myc is a critical function of Aurora A in human neuroblastoma. Cancer Cell 15 (1):67-78. doi:10.1016/ j.ccr.2008.12.005 [PubMed: 19111882]

14. Dar AA, Belkhiri A, El-Rifai W (2009) The aurora kinase A regulates GSK-3beta in gastric cancer cells. Oncogene 28 (6):866-875. doi:10.1038/onc.2008.434 [PubMed: 19060929]

15. Bischoff JR, Anderson L, Zhu Y, Mossie K, Ng L, Souza B, Schryver B, Flanagan P, Clairvoyant F, Ginther C, Chan CS, Novotny M, Slamon DJ, Plowman GD (1998) A homologue of Drosophila aurora kinase is oncogenic and amplified in human colorectal cancers. EMBO J 17 (11):30523065. doi:10.1093/emboj/17.11.3052 [PubMed: 9606188]

16. Wang X, Zhou YX, Qiao W, Tominaga Y, Ouchi M, Ouchi T, Deng CX (2006) Overexpression of aurora kinase $\mathrm{A}$ in mouse mammary epithelium induces genetic instability preceding mammary tumor formation. Oncogene 25 (54):7148-7158. doi:10.1038/sj.onc. 1209707 [PubMed: 16715125]

17. Zhou H, Kuang J, Zhong L, Kuo WL, Gray JW, Sahin A, Brinkley BR, Sen S (1998) Tumour amplified kinase STK15/BTAK induces centrosome amplification, aneuploidy and transformation. Nature genetics 20 (2):189-193. doi:10.1038/2496 [PubMed: 9771714]

18. Nishida N, Nagasaka T, Kashiwagi K, Boland CR, Goel A (2007) High copy amplification of the Aurora-A gene is associated with chromosomal instability phenotype in human colorectal cancers. Cancer biology \& therapy 6 (4):525-533 [PubMed: 17457043]

19. Li D, Zhu J, Firozi PF, Abbruzzese JL, Evans DB, Cleary K, Friess H, Sen S (2003) Overexpression of oncogenic STK15/BTAK/Aurora A kinase in human pancreatic cancer. Clin Cancer Res 9 (3):991-997 [PubMed: 12631597]

20. Kamada K, Yamada Y, Hirao T, Fujimoto H, Takahama Y, Ueno M, Takayama T, Naito A, Hirao S, Nakajima Y (2004) Amplification/overexpression of Aurora-A in human gastric carcinoma: potential role in differentiated type gastric carcinogenesis. Oncology reports 12 (3):593-599 [PubMed: 15289843]

21. Yang SB, Zhou XB, Zhu HX, Quan LP, Bai JF, He J, Gao YN, Cheng SJ, Xu NZ (2007) Amplification and overexpression of Aurora-A in esophageal squamous cell carcinoma. Oncology reports 17 (5):1083-1088 [PubMed: 17390048] 
22. Rojanala S, Han H, Munoz RM, Browne W, Nagle R, Von Hoff DD, Bearss DJ (2004) The mitotic serine threonine kinase, Aurora-2, is a potential target for drug development in human pancreatic cancer. Mol Cancer Ther 3 (4):451 -457 [PubMed: 15078988]

23. Jeng YM, Peng SY, Lin CY, Hsu HC (2004) Overexpression and amplification of Aurora-A in hepatocellular carcinoma. Clin Cancer Res 10 (6):2065-2071 [PubMed: 15041727]

24. Dar AA, Zaika A, Piazuelo MB, Correa P, Koyama T, Belkhiri A, Washington K, Castells A, Pera M, El-Rifai W (2008) Frequent overexpression of Aurora Kinase A in upper gastrointestinal adenocarcinomas correlates with potent antiapoptotic functions. Cancer 112 (8): 1688-1698. doi: 10.1002/cncr.23371 [PubMed: 18311783]

25. Baba Y, Nosho K, Shima K, Irahara N, Kure S, Toyoda S, Kirkner GJ, Goel A, Fuchs CS, Ogino S (2009) Aurora-A expression is independently associated with chromosomal instability in colorectal cancer. Neoplasia 11 (5):418-425 [PubMed: 19412426]

26. Cammareri P, Scopelliti A, Todaro M, Eterno V, Francescangeli F, Moyer MP, Agrusa A, Dieli F, Zeuner A, Stassi G (2010) Aurora-a is essential for the tumorigenic capacity and chemoresistance of colorectal cancer stem cells. Cancer Res 70 (11 ):4655-4665. doi: 10.1158/0008-5472.CAN-09-3953 [PubMed: 20460511]

27. Manfredi MG, Ecsedy JA, Chakravarty A, Silverman L, Zhang M, Hoar KM, Stroud SG, Chen W, Shinde V, Huck JJ, Wysong DR, Janowick DA, Hyer ML, Leroy PJ, Gershman RE, Silva MD, Germanos MS, Bolen JB, Claiborne CF, Sells TB (2011) Characterization of Alisertib (MLN8237), an investigational small-molecule inhibitor of aurora A kinase using novel in vivo pharmacodynamic assays. Clin Cancer Res 17 (24):7614-7624. doi: 10.1158/1078-0432.CCR-11-1536 [PubMed: 22016509]

28. Huck JJ, Zhang M, Hyer ML, Manfredi MG (2008) Anti-tumor activity of the Aurora A inhibitor MLN8237 in diffuse large B-cell lymphoma preclinical models. Blood 112:A1592

29. Sehdev V, Katsha A, Arras J, Peng D, Soutto M, Ecsedy J, Zaika A, Belkhiri A, El- Rifai W (2014) HDM2 regulation by AURKA promotes cell survival in gastric cancer. Clin Cancer Res 20 (1):7686. doi:10.1158/1078-0432.CCR-13-1187 [PubMed: 24240108]

30. Katsha A, Soutto M, Sehdev V, Peng D, Washington MK, Piazuelo MB, Tantawy MN, Manning HC, Lu P, Shyr Y, Ecsedy J, Belkhiri A, El-Rifai W (2013) Aurora kinase A promotes inflammation and tumorigenesis in mice and human gastric neoplasia. Gastroenterology 145 (6): 1312-1322 e1311 -1318. doi:10.1053/j.gastro.2013.08.050 [PubMed: 23993973]

31. Dar AA, Belkhiri A, Ecsedy J, Zaika A, El-Rifai W (2008) Aurora kinase A inhibition leads to p73-dependent apoptosis in p53-deficient cancer cells. Cancer Res 68 (21 ):8998-9004. doi: 10.1158/0008-5472.CAN-08-2658 [PubMed: 18974145]

32. Qi W, Cooke LS, Liu X, Rimsza L, Roe DJ, Manziolli A, Persky DO, Miller TP, Mahadevan D (2011) Aurora inhibitor MLN8237 in combination with docetaxel enhances apoptosis and antitumor activity in mantle cell lymphoma. Biochem Pharmacol 81 (7):881-890. doi: 10.1016/j.bcp. 2011.01.017 [PubMed: 21291867]

33. Zhang M, Huck J, Hyer M, Ecsedy J, Manfredi M (2009) Effect of Aurora A kinase inhibitor MLN8237 combined with rituximab on antitumor activity in preclinical B-cell non-Hodgkin's lymphoma models. Journal of Clinical Oncology 27 (15_suppl):8553- 8553. doi:10.1200/jco. 2009.27.15_suppl.8553

34. Sehdev V, Peng D, Soutto M, Washington MK, Revetta F, Ecsedy J, Zaika A, Rau TT, SchneiderStock R, Belkhiri A, El-Rifai W (2012) The aurora kinase A inhibitor MLN8237 enhances cisplatin-induced cell death in esophageal adenocarcinoma cells. Mol Cancer Ther 11 (3):763774. doi:10.1158/1535-7163.MCT-11-0623 [PubMed: 22302096]

35. Sehdev V, Soutto M, Belkhiri A, Ecsedy J, El-Rifai W (2012) Effect of a combination of aurora kinase A inhibitor MLN-8237 and cisplatin on gastrointestinal tumors. J Clin Oncol 30 (suppl 4; abstr 58)

36. Chibaudel B, Maindrault-Goebel F, Lledo G, Mineur L, Andre T, Bennamoun M, Mabro M, Artru P, Carola E, Flesch M, Dupuis O, Colin P, Larsen AK, Afchain P, Tournigand C, Louvet C, de Gramont A (2009) Can chemotherapy be discontinued in unresectable metastatic colorectal cancer? The GERCOR OPTIMOX2 Study. J Clin Oncol 27 (34):5727-5733. doi:10.1200/JCO. 2009.23.4344 [PubMed: 19786657] 
37. Siegel RL, Miller KD, Jemal A (2017) Cancer Statistics, 2017. CA: a cancer journal for clinicians 67 (1):7-30. doi:10.3322/caac.21387 [PubMed: 28055103]

38. American Cancer Society. Cancer Facts \& Figures 2017. (2017). Atlanta: American Cancer Society

39. Melichar B, Adenis A, Lockhart AC, Bennouna J, Dees EC, Kayaleh O, Obermannova R, DeMichele A, Zatloukal P, Zhang B, Ullmann CD, Schusterbauer C (2015) Safety and activity of alisertib, an investigational aurora kinase A inhibitor, in patients with breast cancer, small-cell lung cancer, non-small-cell lung cancer, head and neck squamous-cell carcinoma, and gastrooesophageal adenocarcinoma: a five-arm phase 2 study. Lancet Oncol 16 (4):395-405. doi: 10.1016/S1470-2045(15)70051-3 [PubMed: 25728526]

40. Matulonis UA, Sharma S, Ghamande S, Gordon MS, Del Prete SA, Ray-Coquard I, Kutarska E, Liu H, Fingert H, Zhou X, Danaee H, Schilder RJ (2012) Phase II study of MLN8237 (alisertib), an investigational Aurora A kinase inhibitor, in patients with platinum-resistant or -refractory epithelial ovarian, fallopian tube, or primary peritoneal carcinoma. Gynecol Oncol 127 (1):63-69. doi:10.1016/j.ygyno.2012.06.040 [PubMed: 22772063]

41. Cervantes A, Elez E, Roda D, Ecsedy J, Macarulla T, Venkatakrishnan K, Rosello S,Andreu J, Jung J, Sanchis-Garcia JM, Piera A, Blasco I, Manos L, Perez-Fidalgo JA, Fingert H, Baselga J, Tabernero J (2012) Phase I pharmacokinetic/pharmacodynamic study of MLN8237, an investigational, oral, selective aurora a kinase inhibitor, in patients with advanced solid tumors. Clin Cancer Res 18 (17):4764-4774. doi:10.1158/1078-0432.CCR-12-0571 [PubMed: 22753585]

42. Graff JN, Higano CS, Hahn NM, Taylor MH, Zhang B, Zhou X, Venkatakrishnan K, Leonard EJ, Sarantopoulos J (2016) Open-label, multicenter, phase 1 study of alisertib (MLN8237), an aurora A kinase inhibitor, with docetaxel in patients with solid tumors. Cancer 122 (16):2524-2533. doi: 10.1002/cncr.30073 [PubMed: 27192055]

43. DuBois SG, Marachelian A, Fox E, Kudgus RA, Reid JM, Groshen S, Malvar J, Bagatell R, Wagner L, Maris JM, Hawkins R, Courtier J, Lai H, Goodarzian F, Shimada H, Czarnecki S, TsaoWei D, Matthay KK, Mosse YP (2016) Phase I Study of the Aurora A Kinase Inhibitor Alisertib in Combination With Irinotecan and Temozolomide for Patients With Relapsed or Refractory Neuroblastoma: A NANT (New Approaches to Neuroblastoma Therapy) Trial. J Clin Oncol 34 (12):1368-1375. doi:10.1200/JCO.2015.65.4889 [PubMed: 26884555]

44. Kelly KR, Ecsedy J, Medina E, Mahalingam D, Padmanabhan S, Nawrocki ST, Giles FJ, Carew JS (2011) The novel Aurora A kinase inhibitor MLN8237 is active in resistant chronic myeloid leukaemia and significantly increases the efficacy of nilotinib. J Cell Mol Med 15 (10):2057-2070. doi:10.1111/j.1582-4934.2010.01218.x [PubMed: 21091633]

45. Manfredi MG, Ecsedy JA, Meetze KA, Balani SK, Burenkova O, Chen W, Galvin KM, Hoar KM, Huck JJ, LeRoy PJ, Ray ET, Sells TB, Stringer B, Stroud SG, Vos TJ, Weatherhead GS, Wysong dR, Zhang M, Bolen JB, Claiborne CF (2007) Antitumor activity of MLN8054, an orally active small-molecule inhibitor of Aurora A kinase. Proc Natl Acad Sci U S A 104 (10):4106-4111. doi: 10.1073/pnas.0608798104 [PubMed: 17360485]

46. Pitts TM, Bradshaw-Pierce EL, Bagby SM, Hyatt SL, Selby HM, Spreafico A, Tentler JJ, McPhillips K, Klauck PJ, Capasso A, Diamond JR, Davis SL, Tan AC, Arcaroli JJ, Purkey A, Messersmith WA, Ecsedy JA, Eckhardt SG (2016) Antitumor activity of the aurora a selective kinase inhibitor, alisertib, against preclinical models of colorectal cancer. Oncotarget 7 (31): 50290-50301. doi:10.18632/oncotarget.10366 [PubMed: 27385211] 


\section{Assessed for eligibility}

\section{Excluded}

14 Enrolled in dose escalation:

3 Level 1

7 Level 2

3 Level 1

2 Excluded, not evaluable for DLT

\section{Evaluable for DLT assessment 0 of 3 experienced DLT at Level 1 2 of 6 experienced DLT at Level 2 0 of 3 experienced DLT at Level 1}

11 Evaluable for response analysis 1 Excluded, no measureable disease

Figure 1. Consolidated Standards of Reporting Trials Diagram.

Study diagram listing number of eligible subjects enrolled onto the study, and numbers of patients in the safety, efficacy, and biomarker correlate analyses. 
A

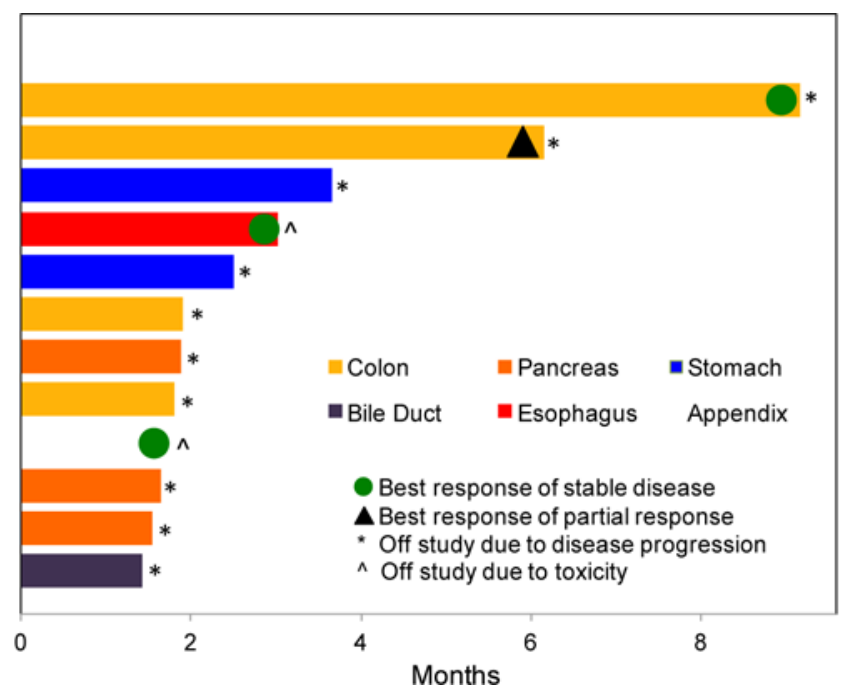

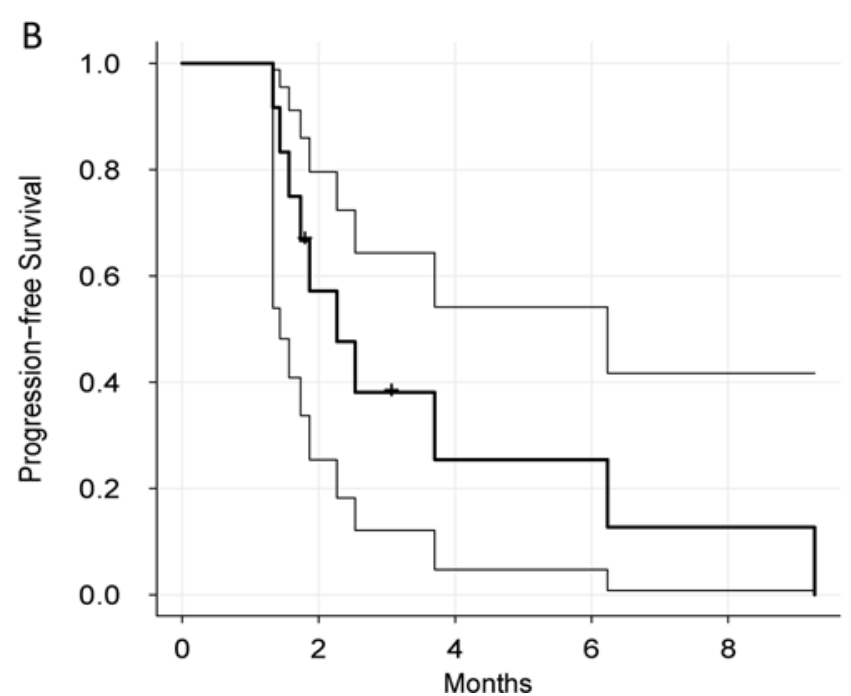

Figure 2. Antitumor Activity of Alisertib in Combination with mFOLFOX.

(A) Swimmer plot showing time on treatment and duration of stable disease or partial response where applicable. (B) Kaplan-Meier analysis for progression-free survival displayed with $95 \%$ CIs. 
Table 1.

Dose Escalation Schema (standard 3+3 design)

\begin{tabular}{lllll}
\hline Dose Level & MLN8237 (Days 1-3) & 5-FU CI (Total given over Days 2-4) & Oxaliplatin (Day 2) & First two cycle (28 days) Toxicity \\
\hline Level 1 $^{*}$ & $10 \mathrm{mg}$ BID & $2400 \mathrm{mg} / \mathrm{m}^{2}$ & $85 \mathrm{mg} / \mathrm{m}^{2}$ & $6 \mathrm{patients;} 0 / 6 \mathrm{with}$ DLT \\
Level 2 & $20 \mathrm{mg}$ BID & $2400 \mathrm{mg} / \mathrm{m}^{2}$ & $85 \mathrm{mg} / \mathrm{m}^{2}$ & $6 \mathrm{patients} ; 2 / 6 \mathrm{with} \mathrm{DLT}+$ \\
Level 3 & $30 \mathrm{mg}$ BID & $2400 \mathrm{mg} / \mathrm{m}^{2}$ & $85 \mathrm{mg} / \mathrm{m}^{2}$ & Not Evaluated \\
Level 4 & $40 \mathrm{mg} \mathrm{BID}$ & $2400 \mathrm{mg} / \mathrm{m}^{2}$ & $85 \mathrm{mg} / \mathrm{m}^{2}$ & Not Evaluated \\
Level 5 & $50 \mathrm{mg}$ BID & $2400 \mathrm{mg} / \mathrm{m}^{2}$ & $85 \mathrm{mg} / \mathrm{m}^{2}$ & Not Evaluated \\
\hline
\end{tabular}

Maximum tolerated dose investigation limited to these levels;

${ }^{+}$Grade 3 fatigue $(n=2)$; Grade 3 nausea, vomiting, dehydration with hospitalization $(n=1)$

CI: continuous infusion; BID: twice daily 
Table 2.

\begin{tabular}{|c|c|c|}
\hline \multirow{6}{*}{ 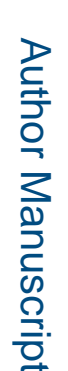 } & \multicolumn{2}{|c|}{ Patient Baseline Characteristics $(n=14)$} \\
\hline & Gender - No. $(\%)$ & \\
\hline & Male & $9(64)$ \\
\hline & Female & $5(36)$ \\
\hline & Median age - No. (range) & $59(27-80)$ \\
\hline & \multicolumn{2}{|l|}{ Race - No. $(\%)$} \\
\hline & White & $8(57)$ \\
\hline & Black & $4(29)$ \\
\hline & Asian & $2(14)$ \\
\hline & \multicolumn{2}{|l|}{ Ethnicity - No. (\%) } \\
\hline & Hispanic & $1(7)$ \\
\hline & Non-hispanic & $12(86)$ \\
\hline 므 & Not Reported & $1(7)$ \\
\hline$\underset{\mathrm{d}}{\zeta}$ & \multicolumn{2}{|l|}{ Primary Site of Disease - No. (\%) } \\
\hline$\stackrel{20}{2}$ & Colon & $4(29)$ \\
\hline $\bar{\varrho}$ & Pancreas & $4(29)$ \\
\hline $\bar{\tau}$ & Stomach & $2(14)$ \\
\hline & Bile Duct & $2(14)$ \\
\hline & Esophagus & $1(7)$ \\
\hline & Appendix & $1(7)$ \\
\hline & \multicolumn{2}{|l|}{ PS (ECOG) - No. (\%) } \\
\hline & 0 & $3(21)$ \\
\hline$=$ & 1 & $11(79)$ \\
\hline
\end{tabular}

PS: performance status; ECOG: Eastern Cooperative Oncology Group 
Table 3.

Treatment-related adverse events reported in $\geq 20 \%$ of patients $(n=14)$

\begin{tabular}{lll}
\hline Adverse Event & All grades & Grade $\mathbf{Z}^{*}$ \\
\hline Non-hematological & $8(57 \%)$ & $1(7 \%)$ \\
Nausea & $6(43 \%)$ & 0 \\
Diarrhea & $6(43 \%)$ & $2(14 \%)$ \\
Fatigue & $6(43 \%)$ & $1(7 \%)$ \\
Peripheral Sensory Neuropathy & $6(43 \%)$ & $1(7 \%)$ \\
Vomiting & $5(36 \%)$ & 0 \\
Anorexia & $4(29 \%)$ & 0 \\
Elevated Alanine Aminotransferase & $3(21 \%)$ & 0 \\
Elevated aspartate Aminotransferase & $3(21 \%)$ & 0 \\
Oral Mucositis & & \\
\hline Hematological & $5(36 \%)$ & $1(7 \%)$ \\
Anemia & $4(29 \%)$ & $4(29 \%)$ \\
Neutropenia & $4(29 \%)$ & 0 \\
Leukopenia & $3(21 \%)$ & 0 \\
Lymphocytopenia & $3(21 \%)$ & 0 \\
Thrombocytopenia &
\end{tabular}

Invest New Drugs. Author manuscript; available in PMC 2020 April 01. 
Table 4.

Best Response According to RECIST for each efficacy evaluable patient

\begin{tabular}{|c|c|c|c|c|c|c|}
\hline $\begin{array}{l}\text { Subject } \\
\text { ID No. }\end{array}$ & Disease Site & Alisertib Dose (BID) & Best Response & Best Percent Change & Reason Off Study & AURKA Status \\
\hline 001 & Pancreas & $10 \mathrm{mg}$ & $\mathrm{PD}$ & $-0.7 \%$ & Toxicity & No Alteration Detected \\
\hline 002 & Bile Duct & $10 \mathrm{mg}$ & $\mathrm{PD}$ & $+12 \%$ & Progression & No Alteration Detected \\
\hline 005 & Esophagus & $20 \mathrm{mg}$ & $\mathrm{SD}$ & $-28 \%$ & Toxicity & Unknown \\
\hline 006 & Colon & $20 \mathrm{mg}$ & $\mathrm{SD}$ & $-6.3 \%$ & Progression & Unknown \\
\hline 007 & Pancreas & $20 \mathrm{mg}$ & $\mathrm{PD}$ & $+24 \%$ & Progression & Unknown \\
\hline 008 & Colon & $20 \mathrm{mg}$ & PR & $-37 \%$ & Progression & AURKA Amplification \\
\hline 009 & Stomach & $20 \mathrm{mg}$ & $\mathrm{SD}$ & $-5.9 \%$ & Progression & No Alteration Detected \\
\hline 010 & Appendix & $20 \mathrm{mg}$ & $\mathrm{SD}$ & $0.0 \%$ & Toxicity & Unknown \\
\hline 011 & Pancreas & $10 \mathrm{mg}$ & $\mathrm{PD}$ & $+28 \%$ & Progression & Unknown \\
\hline 013 & Colon & $10 \mathrm{mg}$ & $\mathrm{PD}$ & $+34 \%$ & Progression & Amplification equivocal \\
\hline 014 & Colon & $10 \mathrm{mg}$ & $\mathrm{PD}$ & $+24 \%$ & Progression & Unknown \\
\hline
\end{tabular}

RECIST: response evaluation criteria in solid tumors; No.: number; BID: twice daily; PD: progressive disease; SD: stable disease; PR: partial response; AURKA: aurora kinase a 